\title{
The unusual experience of managing a severe COVID-19 case at home: what can we do and where do we go?
}

\author{
Ivan Chérrez-Ojeda ${ }^{1,2^{*}}$ D, Emanuel Vanegas ${ }^{1,2}$ and Miguel Felix ${ }^{1,2}$
}

\begin{abstract}
Background: The speed and reach of the COVID-19 pandemic has created special scenarios to be considered, such as those in where patients who meet criteria for hospitalization due to moderate/severe disease cannot be hospitalized due to economic constraints and saturation of national health systems. The aim of this report is to present an unusual case of a severe COVID-19 patient managed at home in a developing country, and to discuss some of the available guidelines and potential therapeutic options for this type of cases.

Case presentation: A 60-year-old female seeking medical attention through teleconsultation presents with profound dyspnea, oppressive chest pain, fatigue, episodic hallucinations, and difficulty sleeping, for what she originally sought medical attention at an ER but could not be admitted due to saturation of the health system. A positive PCR test for COVID-19, and a CT scan of the chest showing bilateral consolidations with ground-glass opacities confirmed the diagnosis. The patient was managed at home, with corticosteroids, nitazoxanide and a single dose of $40 \mathrm{mg}$ of subcutaneous enoxaparin. Colchicine was added the third day of treatment. Standard oxygen therapy through nasal cannula was also recommended. Daily follow-ups were established to monitor for signs of clinical improvement. Two weeks later from the initial consultation the patient presents marked improvement in her symptoms, as well as in her CT scan, which prompted in discontinuation of the medications and the oxygen therapy.

Conclusions: There are several limitations in this report regarding the clinical data and the management, but such limitations do also reflect the state of emergency and the chaos that resides in the health care systems of developing nations. For the ambulatory care of COVID-19 patients, several aspects of disease management may differ from current guidelines and basic requirements may represent a huge challenge to cover. Further research is needed to assist physicians in the daily clinical decision making, to optimize patient outcomes, and to reduce the probability of adverse scenarios of patients with COVID-19 managed in the ambulatory setting.
\end{abstract}

Keywords: Ambulatory care, COVID-19, Developing countries, South America

\footnotetext{
* Correspondence: ivancherrez@gmail.com

'Universidad Espíritu Santo, Km. 2.5 vía La Puntilla, 0901-952 Samborondón, Ecuador

${ }^{2}$ Respiralab Research Group, Guayaquil, Ecuador
}

(c) The Author(s). 2020 Open Access This article is licensed under a Creative Commons Attribution 4.0 International License, which permits use, sharing, adaptation, distribution and reproduction in any medium or format, as long as you give appropriate credit to the original author(s) and the source, provide a link to the Creative Commons licence, and indicate if changes were made. The images or other third party material in this article are included in the article's Creative Commons licence, unless indicated otherwise in a credit line to the material. If material is not included in the article's Creative Commons licence and your intended use is not permitted by statutory regulation or exceeds the permitted use, you will need to obtain permission directly from the copyright holder. To view a copy of this licence, visit http://creativecommons.org/licenses/by/4.0/. The Creative Commons Public Domain Dedication waiver (http://creativecommons.org/publicdomain/zero/1.0/) applies to the data made available in this article, unless otherwise stated in a credit line to the data. 


\section{Background}

To date, the COVID-19 pandemic has affected over 184 countries, representing a global health problem of enormous proportions not only as a health crisis, but one with devastating social and economic implications for years to come [1, 2]. Adding to the already complex scenario are the different responses to the pandemic between countries according to their own strengths and weaknesses, exposing a hard truth: inequality is a threat that will disproportionally hit developing countries [3]. According to a recent report by the World Economic Forum, developing countries suffer from a severe shortage of healthcare workers, as well as a lack of fiscal and monetary capacity to cope with the speed of the pandemic [4]. This in turn leads to a scenario where poverty, overcrowding, and poor public health systems, in combination with the virus, can affect individuals in practically any socioeconomic status and in any society [5].

The spectrum of symptomatic COVID-19 infection ranges from mild to critical, with roughly $80 \%$ of symptomatic patients presenting with mild disease [6]. Studies have found that older patients, with associated comorbidities such as cardiovascular disease, type 2 diabetes, chronic kidney and lung disease, and cancer, are at higher risk for severe and life-threatening disease [6-9]. In the case of severe patients, there are several agents with demonstrated in vitro activity against COVID-19 used in clinical practice, including hydroxychloroquine, remdesivir, interleukin-6 pathway inhibitors, and convalescent plasma; however, to date few agents have proven efficacy against COVID-19 [10]. For instance, a recent preliminary report on the antiviral medication remdesivir, found that it was superior to placebo in shortening the time to recovery among hospitalized adults with COVID-19 with evidence of lower respiratory tract infection, although a reduced mortality benefit was not seen [11]. On the other hand, ambulatory care is usually restricted to patients with asymptomatic to mild disease, and the management is based infection control, and symptomatic relief (e.g. antipyretic medications, and hydration) $[12,13]$.

However, the speed and reach of the pandemic has created special scenarios to be considered, such as those in where patients who meet criteria for hospitalization due to moderate/severe disease cannot be hospitalized due to economic constraints and saturation of national health systems. The aim of this report is to present an unusual case of a severe COVID-19 patient managed at home in a developing country, and to discuss some of the available guidelines and potential therapeutic options for this type of cases.

\section{Case presentation}

A previously healthy 60 -year-old female seeking medical attention through teleconsultation presents with profound dyspnea, oppressive chest pain, fatigue, episodic hallucinations, and difficulty sleeping. The patient describes that her symptoms began 7 days ago with nonproductive cough and fever, later progressing to dyspnea that exacerbated with minimal effort, for what she originally sought medical attention at an ER. At the ER triage the patient presented with profound dyspnea, an oxygen saturation of $86 \%$ at room air, and a respiratory rate of 32 breaths/min. However, despite the severity of the respiratory compromise, the patient could not be admitted due to hospital oversaturation. Unfortunately, the patient was sent home with medical recommendations, including nebulization with normal saline, acetylcysteine and ambroxol hydrochloride. She was also advised that a chest CT scan was needed.

At the medical teleconsultation, the patient presented marked respiratory distress accompanied with a respiratory rate of 31 respirations per minute, and an oxygen saturation of $85 \%$ at room air. A relative of the patient described what is compatible with skin and mucous membrane dryness, skin pallor and bilateral 1+ pitting edema. The patient handed-off a copy of the CT scan where bilateral pulmonary edema and consolidations with ground-glassing were observed encompassing nearly $90 \%$ of the lung parenchyma (Fig. 1a). A basic panel of laboratory tests, and a PCR test for COVID-19 were ordered, the latter of which confirmed the diagnosis (Table 1). She was prescribed with IV normal saline for rehydration, pharmacologic management with IV methylprednisolone (250 mg every $24 \mathrm{~h}$ for 3 days), followed by prednisone (40 mg for 7 days), nitazoxanide (500 mg every $8 \mathrm{~h}$ ) for 7 days and a single dose of $40 \mathrm{mg}$ of subcutaneous enoxaparin, all of which were administered by an outpatient registered nurse at home. Standard oxygen therapy through nasal cannula was also recommended. Medical treatment is best depicted in Fig. 2. Colchicine was added at the third day of treatment ( $2 \mathrm{mg}$ loading dose, followed by $0.5 \mathrm{mg}$ every $8 \mathrm{~h}$ up to the end of treatment).

Daily follow-ups were established to monitor for signs of clinical improvement. Two weeks later from the initial consultation the patient presented marked improvement in her symptoms, as well as in her CT scan (Fig. 1b), which prompted in discontinuation of the medications and the oxygen therapy. At one-month follow-up the patient presented a nearly complete resolution of the initial symptoms, with a partially restored capacity to perform her daily activities. At the 45th day a negative PCR test for the viral RNA was reported. However, spirometry and diffusion capacity for carbon monoxide (DLCO) at 3rd, 4th and 6th months showed results compatible with 


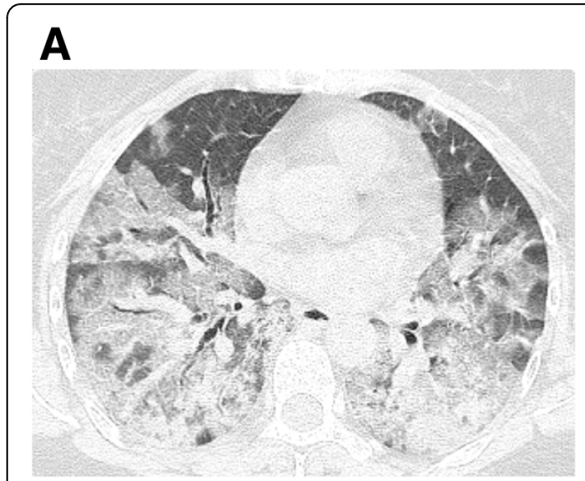

B

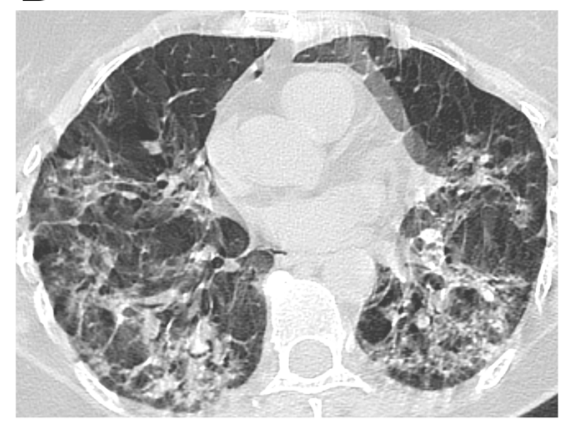

C

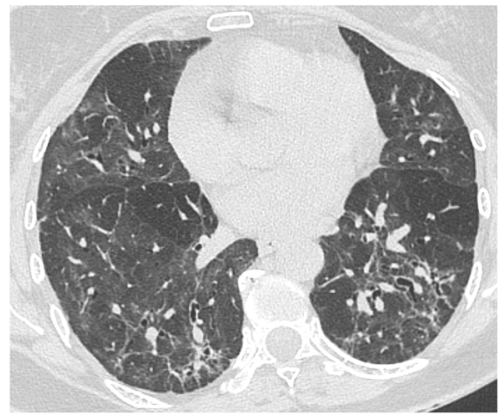

Fig. 1 Computed tomography $(\mathrm{CT})$ scans of the chest. a Initial CT scan showing bilateral ground glass opacities involving most of the lung parenchyma. b Follow-up CT scan 14 days later showing marked improvement from baseline. c Follow-up CT scan at 6 months

a restrictive pattern evidenced by reduced FVC, FEV1 and DLCO measurements with respect to predicted values (Fig. 3, Table 2), while the 6-min walk test showed a decreased walking distance. Radiographic changes persisted at the 6-month follow-up chest CT scan (Fig. 1c).

Table 1 Laboratory parameters at baseline evaluation

\begin{tabular}{|c|c|c|}
\hline Parameter & Result & Reference Range \\
\hline $\mathrm{RBC} \times 10^{3}$ & 4.59 & $3.8-6$ \\
\hline $\mathrm{WBC} \times 10^{3}$ & 21.38 & $3.90-10.80$ \\
\hline Neutrophils $\times 10^{3}$ & 18.77 & $55-75$ \\
\hline Lymphocytes $\times 10^{3}$ & 0.63 & $1.50-4.50$ \\
\hline Monocytes $\times 10^{3}$ & 1.77 & $0.20-0.80$ \\
\hline Eosinophils $\times 10^{3}$ & 0.00 & $0.05-0.50$ \\
\hline Basophils $\times 10^{3}$ & 0.04 & $0.01-0.10$ \\
\hline Platelets K/uL & 492.00 & $150-450$ \\
\hline Sodium (mEq/L) & 135.70 & $135-145$ \\
\hline Potassium (mEq/L) & 4.85 & $3.6-5.2$ \\
\hline Glucose (mg/dL) & 87.80 & $70-100$ \\
\hline $\mathrm{LDH}(\mathrm{U} / \mathrm{L})$ & 466.64 & $140-280$ \\
\hline Ferritin (ng/mL) & 789.40 & $12-300$ \\
\hline D-dimer (ng/mL) & 4578.50 & $<500$ \\
\hline IL-6 (pg/mL) & 42.20 & $5-15$ \\
\hline AST (U/L) & 68.00 & $10-40$ \\
\hline $\operatorname{ALT}(\mathrm{U} / \mathrm{L})$ & 77.00 & $7-56$ \\
\hline $\mathrm{pH}$ & 7.47 & $7.35-7.45$ \\
\hline $\mathrm{PaCO} 2(\mathrm{mmHg})$ & 31.80 & $35-45$ \\
\hline $\mathrm{PaO} 2(\mathrm{mmHg})$ & 47.70 & $80-100$ \\
\hline $\mathrm{HCO} 3(\mathrm{mmol} / \mathrm{L})$ & 22.80 & $22-26$ \\
\hline $\mathrm{SaO} 2(\%)$ & 86.30 & $95-100$ \\
\hline
\end{tabular}

Bolded values represent an out of range parameter

\section{Discussion and conclusions}

The medical literature is vast in tools designed to predict the probabilities of diseases, risk scores to predict prognosis and mortality, and several other methods which are aimed to assist the physician in daily clinical decision making to optimize patient outcomes and reduce adverse scenarios in an objective evidenced-based fashion [14]. Despite the fact that they may be prone to bias, several prediction models for diagnosis and prognosis of COVID-19 disease have been proposed with a good to excellent discriminative performance [15]. For instance, a retrospective study comparing 7 score systems developed for patients with community acquired pneumonia showed that A-DROP was the most reliable tool to stratify hospitalized patients by risk of death [16]. However, other publications have shown that even though scores for community acquired pneumonia provide a good source of therapeutic advice, they tend to underestimate viral infections $[17,18]$. Other scoring systems, like the quick COVID Severity Index (qCSI), have been designed specifically to identify patients that may undergo respiratory deterioration in 24 of admission, whereas others like the Brescia-COVID Respiratory Severity Scale (BCRSS) algorithm may be easily accessible but not externally validated [19-21]. In the outpatient setting however, most of these scoring systems are often too technical and complex, requiring variables that are not easily accessible. This represents a huge challenge that is further complicated by the lack of a definitive and robust guideline.

The CDC and the WHO guidelines recommend high flow nasal cannula (HFNC) in patients that do not respond to conventional oxygen therapy. In a post hoc analysis including 310 patients with acute hypoxemic respiratory failure, HFNC resulted in a lower intubation rate compared to conventional oxygen therapy ( $35 \%$ versus $53 \%$ ) and non-invasive ventilation (35\% versus 58 ) 


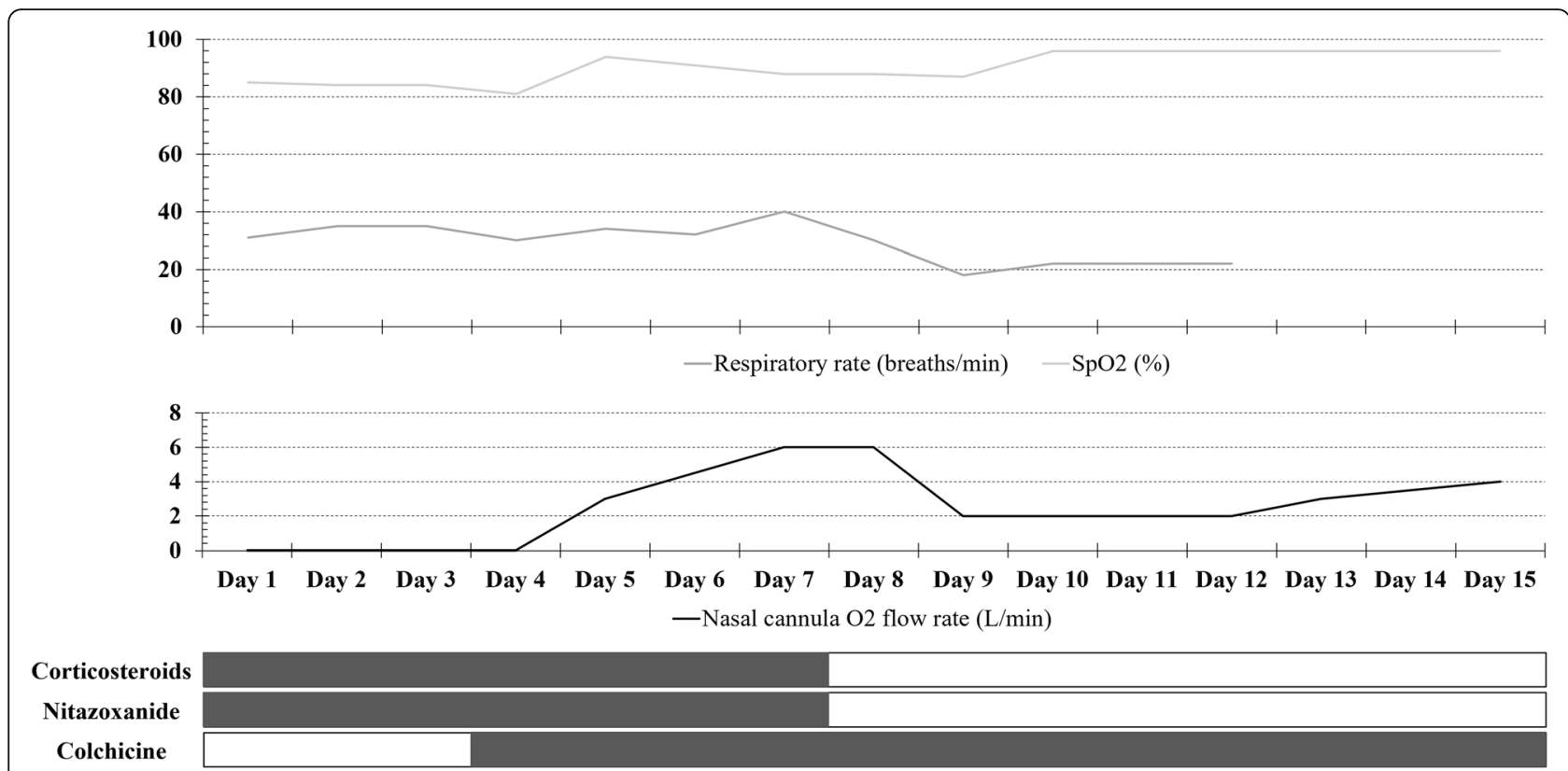

Fig. 2 Timeline of the clinical parameters, oxygen requirement, and management of the patient

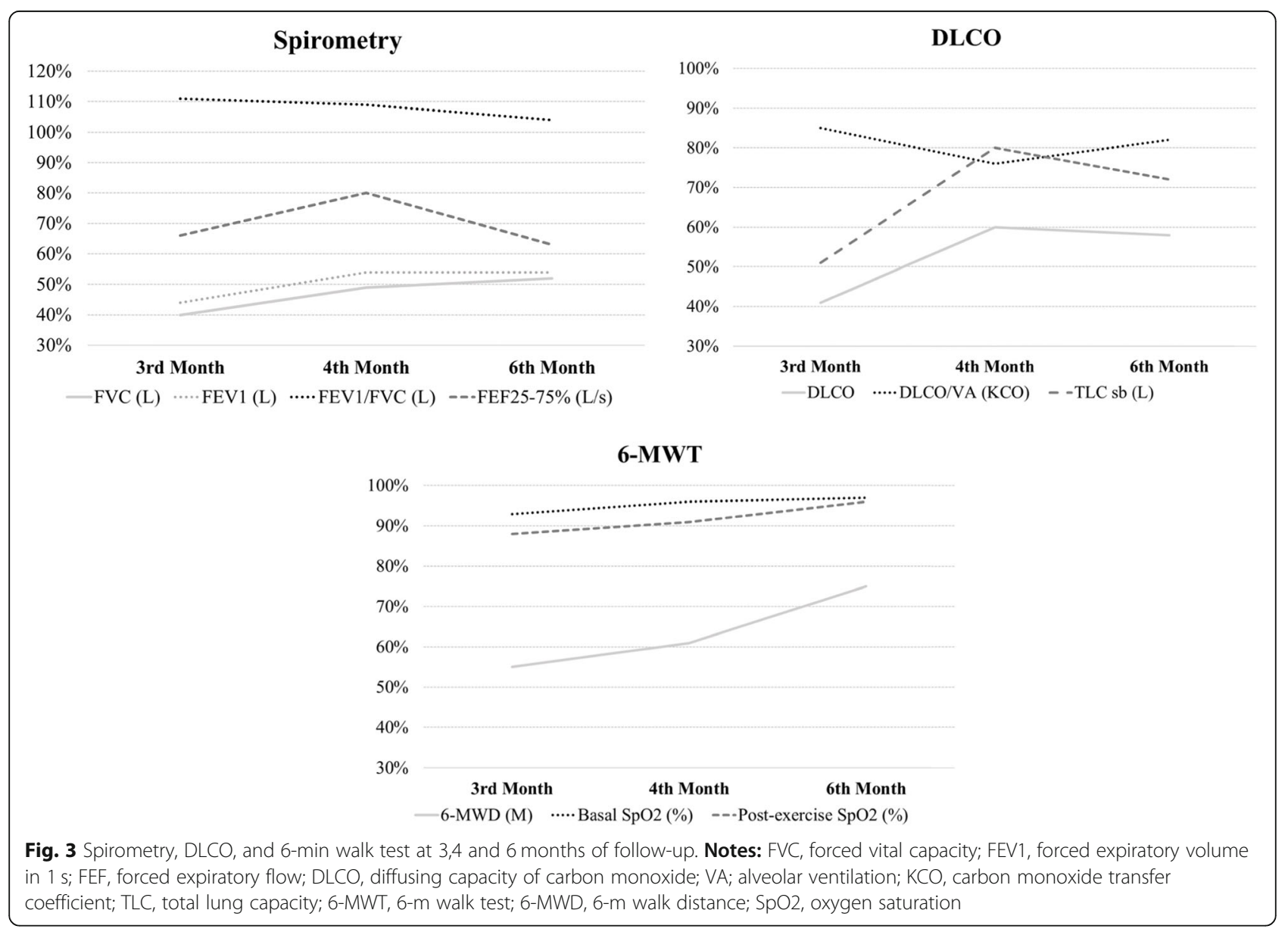


Table 2 Follow-up pulmonary function tests

\begin{tabular}{|c|c|c|c|c|c|c|}
\hline \multicolumn{7}{|l|}{ Pulmonary Function Tests } \\
\hline \multirow{2}{*}{$\begin{array}{l}\text { Month } \\
\text { Parameter }\end{array}$} & \multicolumn{2}{|l|}{ 3rd Month } & \multicolumn{2}{|l|}{ 4th Month } & \multicolumn{2}{|l|}{ 6th Month } \\
\hline & Absolute Value & Predicted (\%) & Absolute Value & Predicted $(\%)$ & Absolute Value & Predicted (\%) \\
\hline \multicolumn{7}{|l|}{ Spirometry } \\
\hline FVC (L) & 1.06 & $40 \%$ & 1.31 & $49 \%$ & 1.38 & $52 \%$ \\
\hline $\mathrm{FEV}_{1}(\mathrm{~L})$ & 0.92 & $44 \%$ & 1.12 & $54 \%$ & 1.13 & $54 \%$ \\
\hline $\mathrm{FEV}_{1} / \mathrm{FVC}(\mathrm{L})$ & 0.87 & $111 \%$ & 86.00 & $109 \%$ & 81.70 & $104 \%$ \\
\hline FEF25-75\% (L/s) & 1.40 & $66 \%$ & 1.71 & $80 \%$ & 1.33 & $63 \%$ \\
\hline \multicolumn{7}{|l|}{ DLCO } \\
\hline DLCO & 8.30 & $41 \%$ & 12.10 & $60 \%$ & 11.70 & $58 \%$ \\
\hline DLCONA (KCO) & 4.52 & $85 \%$ & 4.03 & $76 \%$ & 4.32 & $82 \%$ \\
\hline TLC sb (L) & 2.00 & $51 \%$ & 3.15 & $80 \%$ & 2.86 & $72 \%$ \\
\hline \multicolumn{7}{|l|}{$6-M W T$} \\
\hline 6-MWD (M) & 264 & $55 \%$ & 294 & $61 \%$ & 359 & $75 \%$ \\
\hline Basal SpO2 (\%) & $93 \%$ & N/A & $96 \%$ & N/A & $97 \%$ & N/A \\
\hline Post-exercise SpO2 (\%) & $88 \%$ & N/A & $91 \%$ & N/A & $96 \%$ & N/A \\
\hline
\end{tabular}

FVC forced vital capacity, FEV1 forced expiratory volume in $1 \mathrm{~s}, F E F$ forced expiratory flow, DLCO diffusing capacity of carbon monoxide, VA alveolar ventilation, KCO carbon monoxide transfer coefficient, TLC total lung capacity, 6-MWT 6-m walk test, 6-MWD 6-m walk distance, SpO2 oxygen saturation

[22]. Our patient presented with a $\mathrm{SpO} 2<90 \%$ at 5-6 L/ min at rest for 4 consecutive days with a low-flow nasal cannula, and despite this poor initial response, the patient had to be kept with conventional oxygen therapy due the unavailability of high-flow nasal devices in the outpatient setting. This unfortunate limitation inclined the management to a more prominent pharmacologic approach.

The Infectious Diseases Society of America (IDSA) guidelines recommend remdesivir over no antiviral drug, taking into consideration its in vitro activity against MERS-CoV, SARS-CoV 1 and 2, and a case series including 61 patients where remdesivir was prescribed in a compassionate basis with a $68 \%$ clinical improvement after a median follow-up of 18 days [23-25]. However, given the fact that the former publication was limited by the lack of a standard of care group to compare with, and upon the lack of additional supporting evidence, other guidelines like the WHO do not recommend any antiviral drugs unless patients are participating in a clinical trial. Our patient was not treated with any antiviral medication.

Even though there is insufficient data to recommend either for or against antiviral and immunomodulatory medication in patients with severe respiratory disease due to COVID-19, new evidence in the form of a large scale open-label study (RECOVERY trial) found a decrease in mortality with the use of corticosteroids [26]. In this study, the use of dexamethasone resulted in lower 28-day mortality in hospitalized patients with COVID-19 receiving some form of respiratory support (invasive mechanical ventilation or oxygen alone), compared to patients receiving usual care [26]. It should be noted however, that this benefit was exclusive to patients receiving respiratory support, leading to a change in management from what it was initially proposed by the CDC and the WHO that the use of systemic corticosteroids should be avoided in patients with no evidence of acute respiratory distress syndrome (ARDS). It is uncertain if this patient presented ARDS, however, upon the evidence of deteriorating and progressive disease, she was prescribed with a trial of 3 days of IV methylprednisolone, followed by 7 days of prednisone ( $40 \mathrm{mg} \mathrm{PO})$. At the time the patient presented with severe COVID-19 disease, the decision was taken considering an observational study including 31 patients with mild COVID-19 disease, where no significant association between viral clearance time and corticosteroid treatment (hazard ratio [HR], 1.26; 95\% CI, 0.58-2.74) was reported and indirect evidence in favor of corticosteroids for patients with severe respiratory disease secondary to $\mathrm{H} 1 \mathrm{~N} 1$ and SARS [27-30].

The use of immunomodulators as a strategy to block peripheral inflammation is not a new approach, but questions on its effectiveness to treat patients with COVID-19 remains open [31]. Currently, besides corticosteroids, no official guideline supports the routine use of immunomodulatory medications outside of the context of a clinical trial. Several agents are under active investigation as possible treatments, including interleukin1 and 6 receptor blockers. In a small prospective cohort study the use of the interleukin-1 receptor blocker (anakinra) was associated with a reduced need for invasive mechanical ventilation in the ICU and mortality, 
although there are several limitations of this study that need to be addressed in clinical trials to further support these findings [32]. In the case of the interleukin-6 pathway inhibitor tocilizumab, early observational studies suggest a potential benefit in patients with COVID-19 and elevated pro-inflammatory cytokines (often referred to as "cytokine storm syndrome") [33-35].

Our patient was started on colchicine. Colchicine can either inhibit microtubule assembly at intermediate doses or lead to depolymerization at high doses $[36,37]$. These mechanisms are responsible for the expansive and complex pharmacodynamics of this drug, where its role as a modulator of cytokine signaling cascades and expression of extracellular mediators and receptors are perhaps of most interest in COVID-19 disease [36]. In a recent open-label, randomized clinical trial, the use of colchicine was associated with an improved time to clinical deterioration when compared to standard of care among hospitalized patients with COVID-19, however no difference was observed among biochemical endpoints between groups [38]. Several terms like "cytokine storm", hyperinflammatory or secondary hemophagocytic lymphohistiocytosis-like syndrome have been extensively applied to describe a late and more severe course of COVID-19 infection, and as an inhibitor of NLRP3 inflammasomes and interleukin activation mitigator, colchicine may represent a viable alternative when tocilizumab is unavailable [39-42]. As a matter of fact, in the vascular tissue colchicine has shown to downregulate interleukin-1 and tumor necrosis factor alpha which are upstream mediators of IL-6, the main target of tocilizumab [43, 44]. Even though we cannot confirm it, our patient presented abnormally elevated ferritin, D-dimer, CRP, LDH, transaminases and IL-6, all of which are classic characteristics of this hyperimmune state, justifying to a certain extent the rational use of colchicine [45].

The inpatient management of COVID-19 patients has not yet been established with a high level of evidence, and certainly the care of severe disease in the outpatient setting is less clear. There are several limitations in this report regarding the clinical data and the management, but such limitations do also reflect the state of emergency and the chaos that resides in the health care systems of developing nations. For the ambulatory care of COVID-19 patients, several aspects of disease management may differ from current guidelines and basic requirements may represent a huge challenge to cover. Further research is needed to assist physicians in the daily clinical decision making, to optimize patient outcomes, and to reduce the probability of adverse scenarios of patients with COVID-19 managed in the ambulatory setting.

\section{Abbreviations}

WHO: World Health Organization; CDC: Centers for Disease Control and Prevention; BCRSS: Brescia-COVID Respiratory Severity Scale; ARDS: Acute respiratory distress syndrome; HFNC: High-flow nasal cannula

\section{Acknowledgments}

Special thanks to all members of Respiralab Research Group. We also want to express our gratitude to Universidad Espiritu Santo for their continuous support.

\section{Authors' contributions}

$\mathrm{ICO}, \mathrm{EV}$, and MF developed the research question for the case report and participated in the data collection process. ICO interviewed the patient and oversaw the informed consent. EV, and MF wrote the manuscript, and drafted the final tables and figures. All authors read and approved the manuscript before submission.

\section{Funding}

This study was supported by an unrestricted grant from the Universidad Espíritu Santo. The sponsor had no role in the design of the study or in the collection, analysis, and interpretation of data.

Availability of data and materials

Not applicable.

Ethics approval and consent to participate

Not applicable.

\section{Consent for publication}

Written informed consent was obtained from the patient for the publication of the case report, and any accompanying images. A copy of the written consent is available for review by editors if required.

\section{Competing interests}

The authors declare that they have no competing interests in relation to this work.

Received: 3 June 2020 Accepted: 10 November 2020

Published online: 19 November 2020

\section{References}

1. CSSE J. Coronavirus COVID-19 Global Cases by the Center for Systems Science and Engineering (CSSE) at Johns Hopkins University (JHU). 2020-0315]. https://www.arcgis.com/apps/opsdashboard/index.htm|\#/bda759474 Ofd40299423467b48e9ecf6. Accessed 11 May 2020.

2. World Health Organization. Coronavirus disease 2019 (COVID-19): situation report, 72. 2020.

3. United Nations Development Programme. COVID-19: looming crisis in developing countries threatens to devastate economies and ramp up inequality. UNDP. https://www.undp.org/content/undp/en/home/newscentre/news/2020/COVID19_Crisis_in_developing_countries_threatens_ devastate_economies.html. Accessed 4 May 2020.

4. World Economic Forum. COVID-19: What are the biggest concerns for the developing world? World Economic Forum. 2020. https://www.weforum. org/agenda/2020/04/developing-world-covid19/. Accessed 21 May 2020

5. Mckibbin WJ, Fernando R. The global macroeconomic impacts of COVID-19: seven scenarios; 2020

6. Wu Z, McGoogan JM. Characteristics of and important lessons from the coronavirus disease 2019 (COVID-19) outbreak in China: summary of a report of 72314 cases from the Chinese Center for Disease Control and Prevention. Jama. 2020;323:1239-42.

7. Zhou F, Yu T, Du R, Fan G, Liu Y, Liu Z, et al. Clinical course and risk factors for mortality of adult inpatients with COVID-19 in Wuhan, China: a retrospective cohort study. Lancet. 2020;395:10229.

8. Chow N, Fleming-Dutra K, Gierke R, Hall A, Hughes M, Pilishvili T, et al. Preliminary estimates of the prevalence of selected underlying health conditions among patients with coronavirus disease 2019-United States, February 12-March 28, 2020. Morb Mortal Wkly Rep. 2020;69:382.

9. Liang W, Guan W, Chen R, Wang W, Li J, Xu K, et al. Cancer patients in SARS-CoV-2 infection: a nationwide analysis in China. Lancet Oncol. 2020;21: 335-7. 
10. Kim AY. Coronavirus disease 2019 (COVID-19): management in adults UpToDate. 2020. https://www.uptodate.com/contents/coronavirus-disease-2 019-covid-19-management-in-adults. Accessed 13 Apr 2020

11. Beigel JH, Tomashek KM, Dodd LE, Mehta AK, Zingman BS, Kalil AC, et al. Remdesivir for the treatment of Covid-19_preliminary report. N Engl J Med. 2020;383:10.

12. CDC. Outpatient and ambulatory care settings: responding to community transmission of COVID-19 in the United States: Centers for Disease Control and Prevention; 2020. https://www.cdc.gov/coronavirus/2019-ncov/hcp/ ambulatory-care-settings.html. Accessed 21 May 2020.

13. Centers for Disease Control and Prevention. Interim Clinical Guidance for Management of Patients with Confirmed Coronavirus Disease (COVID-19): Centers for Disease Control and Prevention; 2020. https://www.cdc.gov/ coronavirus/2019-ncov/hcp/clinical-guidance-management-patients.html. Accessed 21 May 2020

14. Koopman RJ, Mainous A. Evaluating multivariate risk scores for clinical decision making. Fam Med-Kansas City- 2008:40:412.

15. Wynants L, Van Calster B, Bonten MM, Collins GS, Debray TP, De Vos M, et al. Prediction models for diagnosis and prognosis of covid-19 infection: systematic review and critical appraisal. Bmj. 2020;369:1-24.

16. Fan G, Tu C, Zhou F, Liu Z, Wang Y, Song B, et al. Comparison of severity scores for COVID-19 patients with pneumonia: a retrospective study. Eur Respir J. 2020;56:1-4.

17. Shi SJ, Li H, Liu M, Liu YM, Zhou F, Liu B, et al. Mortality prediction to hospitalized patients with influenza pneumonia: $\mathrm{PO} 2 / \mathrm{FiO} 2$ combined lymphocyte count is the answer. Clin Respir J. 2017;11:352-60.

18. Guo L, Wei D, Wu Y, Zhou M, Zhang X, Li Q, et al. Clinical features predicting mortality risk in patients with viral pneumonia: the MuLBSTA score. Front Microbiol. 2019;10:2752.

19. Duca A, Piva S, Focà E, Latronico N, Rizzi M. Calculated decisions: BresciaCOVID respiratory severity scale (BCRSS)/algorithm. Emerg Med Pract. 2020; 22(5 Suppl):CD1-2.

20. Lombardia SR. Linee guida sulla gestione terapeutica e di supporto per pazienti con infezione da coronavirus COVID-19. 2.0 ed; 2020.

21. Haimovich A, Ravindra NG, Stoytchev S, Young HP, PerryWilson F, van Dijk D, et al. Development and validation of the quick COVID-19 severity index (qCSI): a prognostic tool for early clinical decompensation. Ann Emerg Med. 2020;76:4

22. Frat J-P, Thille AW, Mercat A, Girault C, Ragot S, Perbet S, et al. High-flow oxygen through nasal cannula in acute hypoxemic respiratory failure. $\mathrm{N}$ Engl J Med. 2015;372:2185-96.

23. Bhimraj A, Morgan RL, Shumaker AH, Lavergne V, Baden L, Cheng VC-C, et al. Infectious diseases Society of America guidelines on the treatment and management of patients with COVID-19. Clin Infect Dis. 2020.

24. Sheahan TP, Sims AC, Graham RL, Menachery VD, Gralinski LE, Case JB, et al. Broad-spectrum antiviral GS-5734 inhibits both epidemic and zoonotic coronaviruses. Sci Transl Med. 2017;9:1-10.

25. Grein J, Ohmagari N, Shin D, Diaz G, Asperges E, Castagna A, et al. Compassionate use of remdesivir for patients with severe Covid-19. N Engl J Med. 2020;382:2327-36.

26. Horby P, Lim WS, Emberson JR, Mafham M, Bell JL, Linsell L, et al. Dexamethasone in hospitalized patients with Covid-19-preliminary report. N Engl J Med. 2020. ahead of print.

27. Zha L, Li S, Pan L, Tefsen B, Li Y, French N, et al. Corticosteroid treatment of patients with coronavirus disease 2019 (COVID-19). Med J Aust. 2020;212:9.

28. Long $Y, X u Y$, Wang B, Zhang $L$, Jia D, Xue F, et al. Clinical recommendations from an observational study on MERS: glucocorticoids was benefit in treating SARS patients. Int J Clin Exp Med. 2016;9:8865-73.

29. Li H, Yang S, Gu L, Zhang Y, Yan X, Liang Z, et al. Effect of low-to-moderatedose corticosteroids on mortality of hospitalized adolescents and adults with influenza A (H1N1) pdm09 viral pneumonia. Influenza Other Respir Viruses. 2017;11:345-54.

30. Liu J, Zheng $X$, Huang Y, Shan H, Huang J. Successful use of methylprednisolone for treating severe COVID-19. J Allergy Clin Immunol. 2020. https://doi.org/10.1016/j.jaci.2020.05.021.

31. Khan NA. Anakinra for severe forms of COVID-19. Lancet Rheumatol. 2020;2: 10

32. Huet $\mathrm{T}$, Beaussier $\mathrm{H}$, Voisin $\mathrm{O}$, Jouveshomme $\mathrm{S}$, Dauriat $\mathrm{G}$, Lazareth $\mathrm{I}$, et al. Anakinra for severe forms of COVID-19: a cohort study. Lancet Rheumatol. 2020:2:10
33. Klopfenstein T, Zayet S, Lohse A, Balblanc J-C, Badie J, Royer P-Y, et al. Tocilizumab therapy reduced intensive care unit admissions and/or mortality in COVID-19 patients. Med Mal Infect. 2020;50:5.

34. Sciascia S, Aprà F, Baffa A, Baldovino S, Boaro D, Boero R, et al. Pilot prospective open, single-arm multicentre study on off-label use of tocilizumab in severe patients with COVID-19. Clin Exp Rheumatol. 2020;38: 529-32.

35. Guaraldi G, Meschiari M, Cozzi-Lepri A, Milic J, Tonelli R, Menozzi M, et al. Tocilizumab in patients with severe COVID-19: a retrospective cohort study. Lancet Rheumatol. 2020;2:e474-84.

36. Slobodnick A, Shah B, Pillinger MH, Krasnokutsky S. Colchicine: old and new. Am J Med. 2015;128:461-70.

37. Casanova P, Artola RT, Mihos CG, Pineda AM, Santana O. The cardiovascular effects of colchicine: a comprehensive review. Cardiol Rev. 2015;23:317-22.

38. Deftereos SG, Giannopoulos G, Vrachatis DA, Siasos GD, Giotaki SG, Gargalianos P, et al. Effect of colchicine vs standard care on cardiac and inflammatory biomarkers and clinical outcomes in patients hospitalized with coronavirus disease 2019: the GRECCO-19 randomized clinical trial. JAMA Netw Open. 2020;3:e2013136

39. Mehta P, McAuley DF, Brown M, Sanchez E, Tattersall RS, Manson JJ. COVID19: consider cytokine storm syndromes and immunosuppression. Lancet. 2020:395:1033-4.

40. Toniati P, Piva S, Cattalini M, Garrafa E, Regola F, Castelli F, et al. Tocilizumab for the treatment of severe COVID-19 pneumonia with hyperinflammatory syndrome and acute respiratory failure: A single center study of 100 patients in Brescia, Italy. Autoimmun Rev. 2020;19(7):102568.

41. Karakike E, Giamarellos-Bourboulis EJ. Macrophage activation-like syndrome: a distinct entity leading to early death in sepsis. Front Immunol. 2019;10:110.

42. Misawa T, Takahama M, Kozaki T, Lee H, Zou J, Saitoh T, et al. Microtubuledriven spatial arrangement of mitochondria promotes activation of the NLRP3 inflammasome. Nat Immunol. 2013;14:454.

43. Hoffman HM. Therapy of autoinflammatory syndromes. J Allergy Clin Immunol. 2009;124:1129-38.

44. Ridker PM, Lüscher TF. Anti-inflammatory therapies for cardiovascular disease. Eur Heart J. 2014;35:1782-91.

45. Ramos-Casals M, Brito-Zerón P, López-Guillermo A, Khamashta MA, Bosch X Adult haemophagocytic syndrome. Lancet. 2014;383:1503-16.

\section{Publisher's Note}

Springer Nature remains neutral with regard to jurisdictional claims in published maps and institutional affiliations.

Ready to submit your research? Choose BMC and benefit from:

- fast, convenient online submission

- thorough peer review by experienced researchers in your field

- rapid publication on acceptance

- support for research data, including large and complex data types

- gold Open Access which fosters wider collaboration and increased citations

- maximum visibility for your research: over $100 \mathrm{M}$ website views per year

At $\mathrm{BMC}$, research is always in progress.

Learn more biomedcentral.com/submissions 